\title{
Surface Morphologies of Chemically Treated Hydroxyapatite
}

\author{
P. L. FAN, W. J. O'BRIEN, M. C. WALKER IV
}

\section{The University of Michigan, School of Dentistry, Ann Arbor, Michigan 48109}

$J$ Dent Res 58(6): 1566-1569, June 1979

Synthetic hydroxyapatite is often used for simulation studies of adsorption of Streptococcus mutans and other oral bacteria. Effects of chemical treatments of hydroxyapatites on the adsorption of $S$. mutans have been reported (O'Brien et al., $J$ Dent Res Sept 1978; McIntyre et al., J Dent Res 57, Special Issue $\mathrm{A}, 178,1978)$. The amount of bacteria adsorbed by a known weight of chemically treated hydroxyapatite is influenced by the surface

Received for publication August 14, 1978.

Accepted for publication August 30,1978 .

This research was supported by Research Grant DE 03480 from the National Institutes of Health, National Institute of Dental Research, Bethesda, Maryland, 20014. area of the hydroxyapatite powder. A practical method of detecting gross changes in surface area is by examining the surface morphologies of the chemically treated hydroxyapatite powder using scanning electron microscopy.

Hydroxyapatite powders* $(15 \mathrm{mg})$ were treated with $0.5 \mathrm{ml}$ of one of the following chemical solutions: $0.2 \%$ chlorhexidine gluconate $\dagger ; 2 \%$ dextran (molecular weight 40,000) $\ddagger, 0.2 \mathrm{M} \mathrm{NaF} \$ ; 0.005 \mathrm{M}$

*Bio gel HTP, Bio-Rad Laboratories, Richmond, CA, USA

Imperial Chemical Industries, Holland

† Pharmacia Fine Chemicals AB, Uppsala, Sweden

$\S$ J. T. Baker Chemical Company, Phillipsburg, NJ, USA

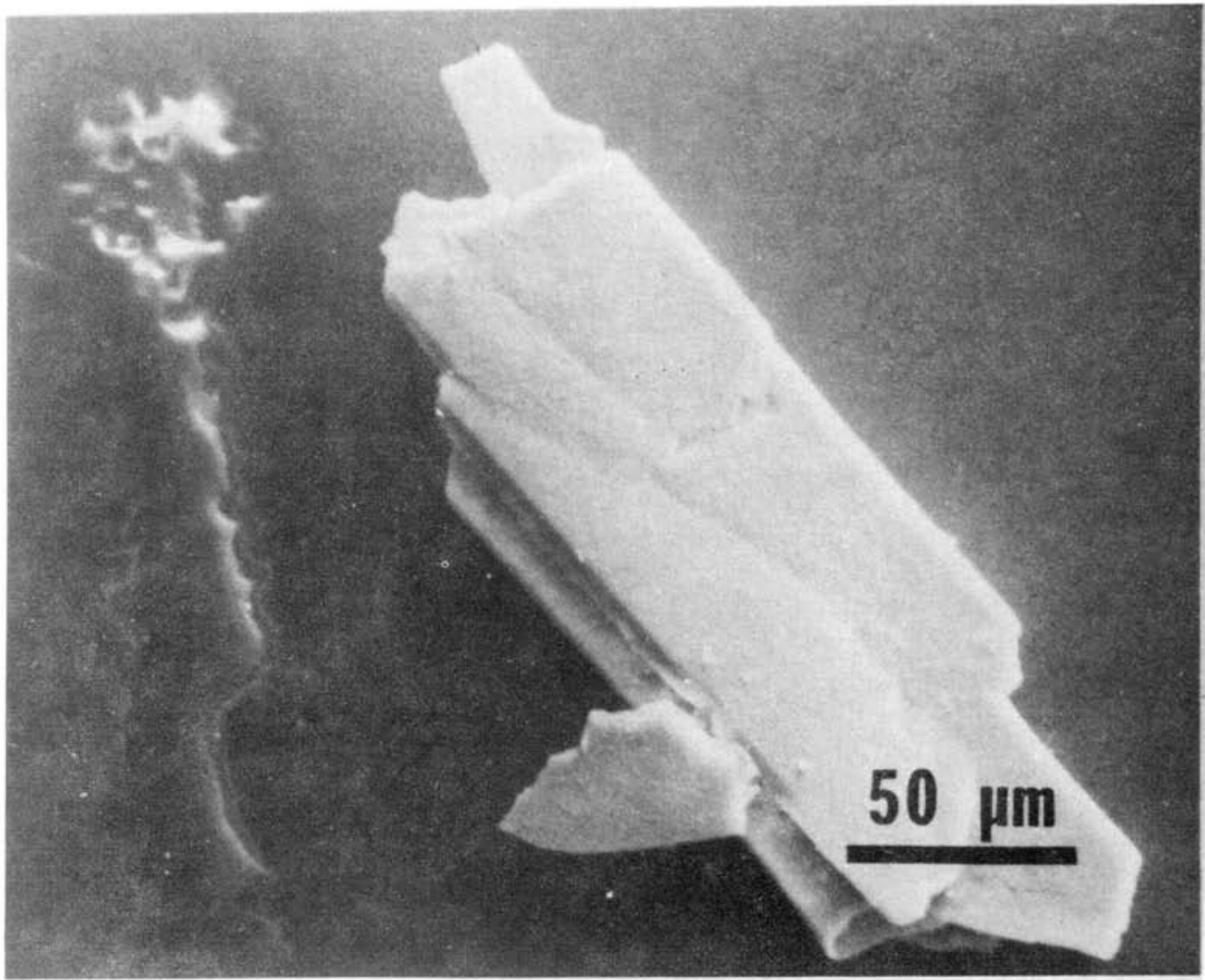

Figs. 1-5.-Scanning electron micrographs of hydroxyapatite treated with 1) chlorhexidine gluconate, 2) dextran, 3) distilled water, 4) $\mathrm{NaF}, 5)$ tetradecylamine acetate. 
tetradecylamine acetate ${ }^{\infty}$; and distilled water as a control. Procedures for chemical treatments and $S$. mutans adsorption have been previously described (O'Brien et al., op. cit.).

The surfaces of the chemically-treated hydroxyapatite powders, without $S$. mutans adsorption, were studied by scanning electron microscopy. The powders were dried, coated with gold by vapor deposition and examined in a scanning electron microscope 1 .

The number of $S$. mutans organisms $\left(\times 10^{8}\right)$ adsorbed by $1 \mathrm{mg}$ of chemically-treated hydroxyapatite were (standard deviations in parentheses): chlorhexidine gluconate, 2.90 (1.19); dextran, $3.56(0.45)$; distilled water, $4.35(0.88)$; NaF, 6.87 $(0.40)$; and tetradecylamine acetate, $7.23(0.43)$. The corresponding scanning electron micrographs of the chemically-treated hydroxyapatite are shown in Figures 1 through 5, respectively. The results showed decreases in adsorption of $S$. mutans on hydroxyapatite treated with chlorhexidine gluconate or dextran when compared with treatments with distilled water. Scanning electron

$\infty$ Eastman Organic Chemicals, Rochester, NY, USA

International Scientific Instruments, Inc., Mountain View, CA, USA microscopy of these treated powders showed no detectable change in surface morphology (Fig. 1-3); the hydroxyapatites were in platelet form. However, when hydroxyapatite powders were treated with NaF or tetradecylamine acetate, adsorption of $S$. mutans increased by $58 \%$ and $66 \%$, respectively, compared with hydroxyapatite powders treated with distilled water. Corresponding scanning electron micrographs of the treated powders showed observable changes in surface morphology. Hydroxyapatite powders treated with $\mathrm{NaF}$ (Fig. 4) contained smaller granular particles in addition to platelets. These granules were absent in hydroxyapatite treated with distilled water. The process reduced the average particle size and increased the number of particles, resulting in an increase in the surface area available for $S$. mutans adsorption. Treatment of hydroxyapatite by tetradecylamine acetate resulted in small needle-like projections on the surface. This change in surface morphology would also result in an increase in surface area and an increase in $S$. mutans adsorption. Thus, observable changes in surface morphologies of chemically-treated hydroxyapatite would influence quantitative bacterial adsorption experiments.

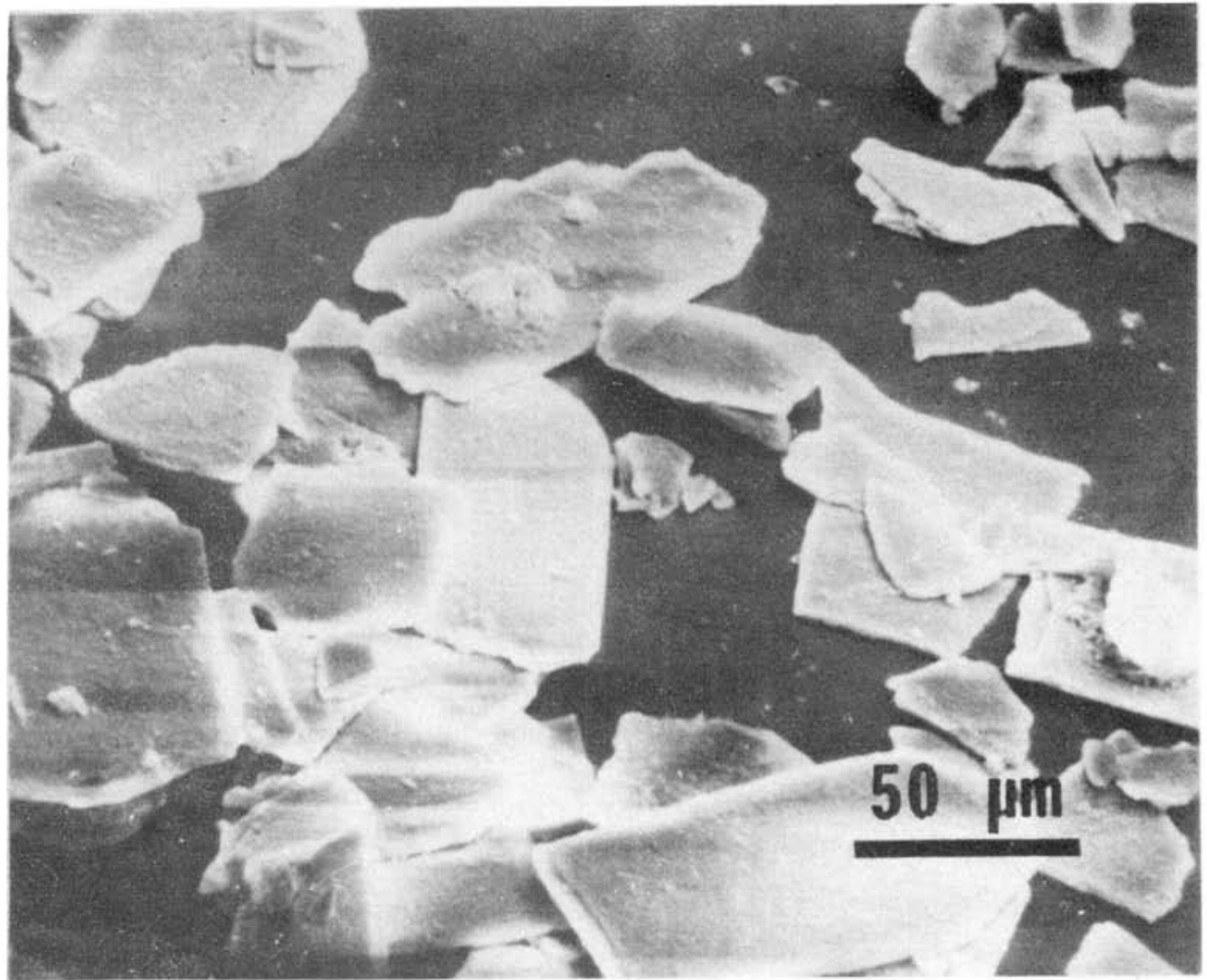




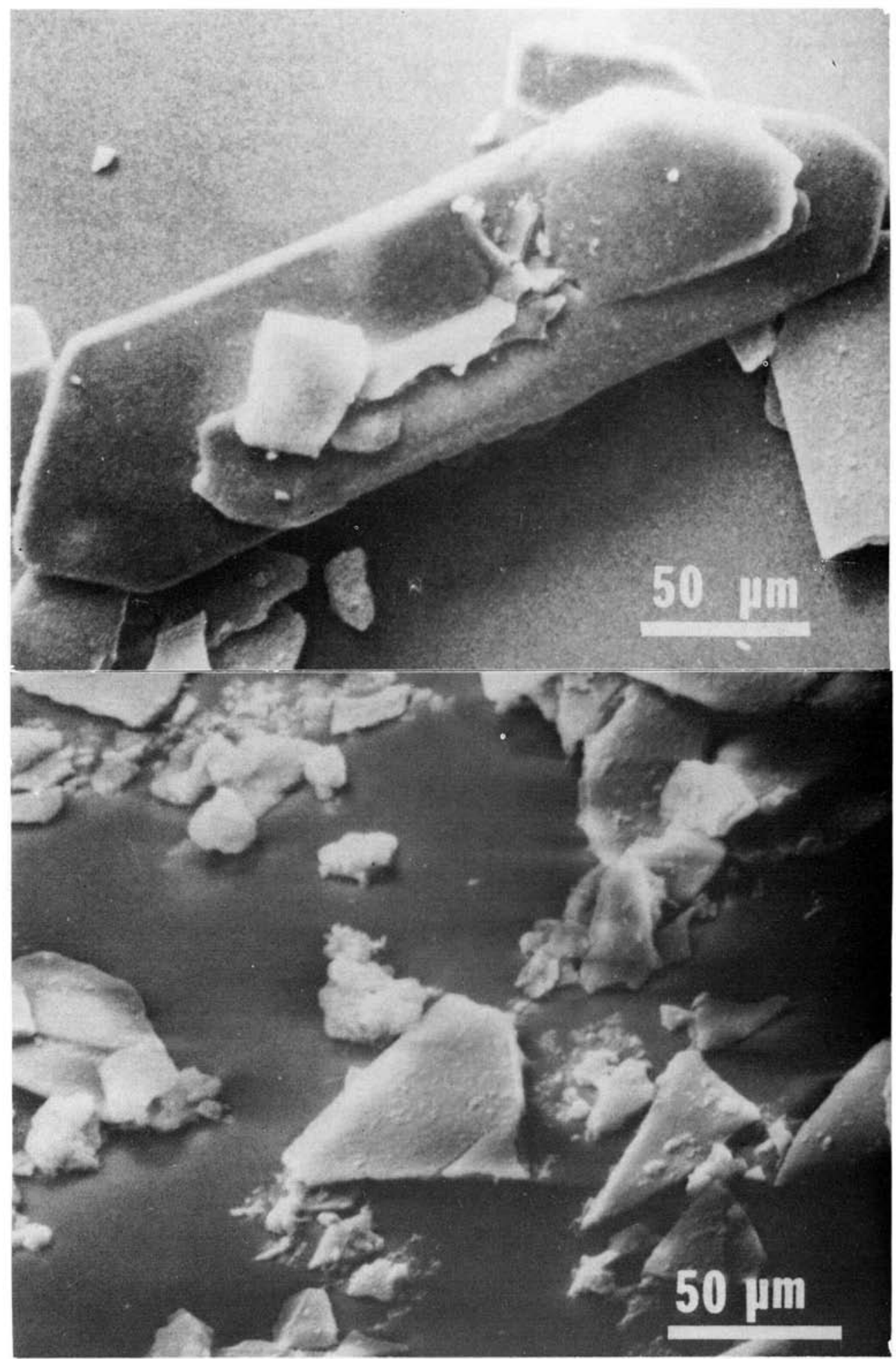




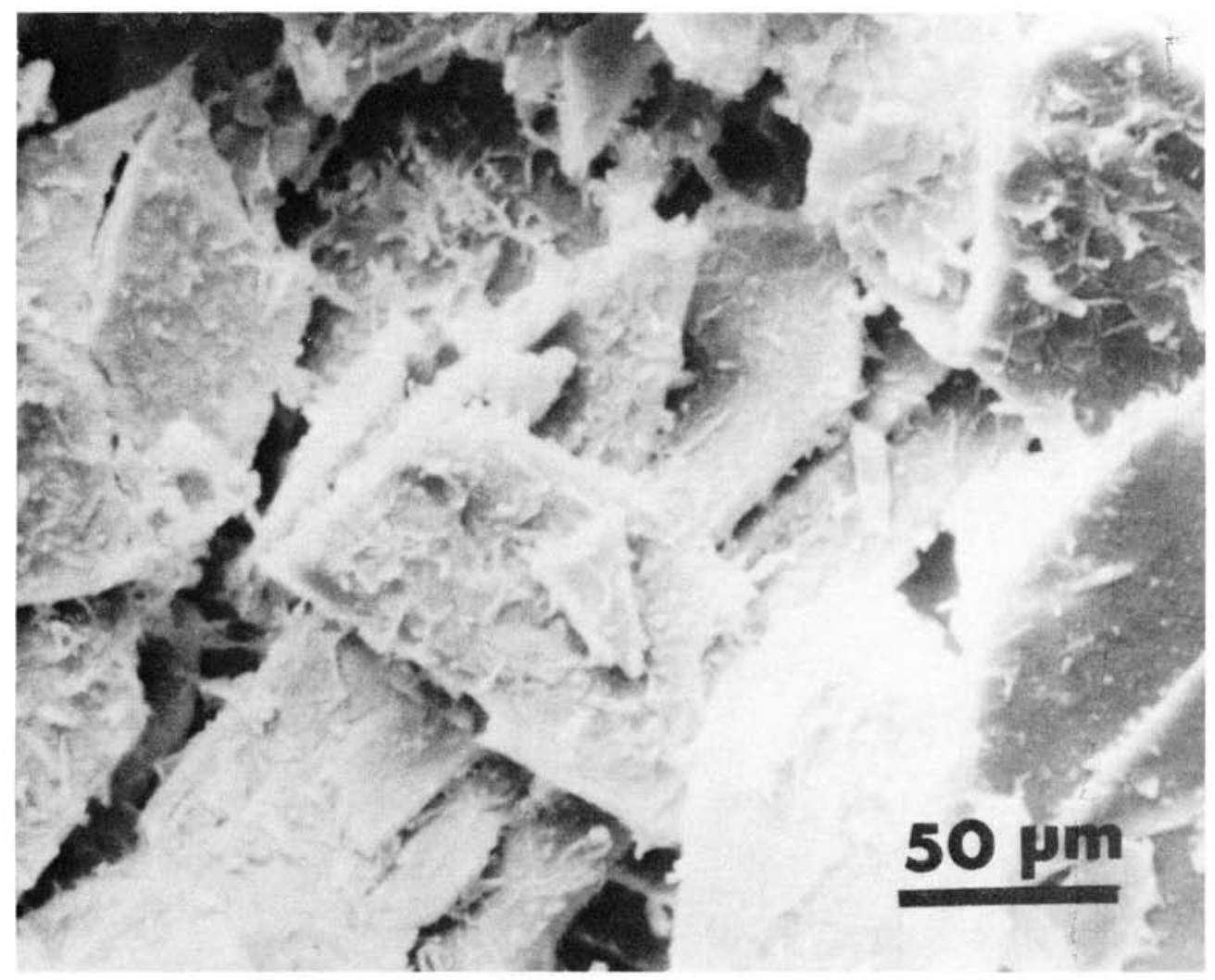

